\title{
Genetically modifying skin microbe to produce violacein and augmenting microbiome did not defend Panamanian golden frogs from disease
}

\author{
Matthew H. Becker ${ }^{1,7}$, Jennifer A. N. Brophy ${ }^{2}{ }^{2}$, Kevin Barrett ${ }^{3}$, Ed Bronikowski ${ }^{4}$, Matthew Evans ${ }^{4}$, Emerson Glassey ${ }^{2}$, \\ Alyssa W. Kaganer ${ }^{1}$, Blake Klocke ${ }^{1,5}$, Elliot Lassiter ${ }^{4}$, Adam J. Meyer ${ }^{2}$, Carly R. Muletz-Wolz ${ }^{6}$, Robert C. Fleischer ${ }^{6}$, \\ Christopher A. Voigt ${ }^{2}$ and Brian Gratwicke $\mathbb{D}^{1 凶}$
}

This is a U.S. government work and not under copyright protection in the U.S.; foreign copyright protection may apply 2021, corrected publication 2022

We designed two probiotic treatments to control chytridiomycosis caused by Batrachochytrium dendrobatidis (Bd) on infected Panamanian golden frogs (Atelopus zeteki), a species that is thought to be extinct in the wild due to Bd. The first approach disrupted the existing skin microbe community with antibiotics then exposed the frogs to a core golden frog skin microbe (Diaphorobacter sp.) that we genetically modified to produce high titers of violacein, a known antifungal compound. One day following probiotic treatment, the engineered Diaphorobacter and the violacein-producing pathway could be detected on the frogs but the treatment failed to improve frog survival when exposed to Bd. The second approach exposed frogs to the genetically modified bacterium mixed into a consortium with six other known anti-Bd bacteria isolated from captive $A$. zeteki, with no preliminary antibiotic treatment. The consortium treatment increased the frequency and abundance of three probiotic isolates (Janthinobacterium, Chryseobacterium, and Stenotrophomonas) and these persisted on the skin 4 weeks after probiotic treatment. There was a temporary increase in the frequency and abundance of three other probiotics isolates (Masillia, Serratia, and Pseudomonas) and the engineered Diaphorobacter isolate, but they subsequently disappeared from the skin. This treatment also failed to reduce frog mortality upon exposure.

ISME Communications (2021)1:57; https://doi.org/10.1038/s43705-021-00044-w

\section{INTRODUCTION}

Chytridiomycosis, a disease caused by the fungal pathogen Batrachochytrium dendrobatidis (Bd), is responsible for the presumed extinction of 90 amphibian species and has devastated amphibian populations around the globe, particularly in the mountainous neotropics [1]. Harlequin toads of the genus Atelopus have been among the taxa most impacted by this disease $[2,3]$, and the Panamanian golden frog Atelopus zeteki is thought to be extinct in the wild as a result of chytridiomycosis-related declines, but large ex-situ populations have prevented their extinction [3].

Despite one unique example of eliminating $\mathrm{Bd}$ in nature [4], there is a dearth of effective solutions available to control the amphibian chytrid fungus in wild situations [5]. In other disease systems, probiotic therapies have controlled diseases through different mechanisms including (i) modulating host innate immunity or inflammatory responses [6,7]; (ii) reducing the ability of a vector host to transmit the disease [8]; (iii) restoring disrupted microbiomes that usually have a protective function [9]; (iv) directly inhibiting pathogen growth [10-12]; or (v) neutralizing pathogen toxins [13]. Genetic engineering tools have allowed further development of designer probiotic therapies that could have enormous potential applications for managing disease $[14,15]$. Examples include symbionts that have been genetically engineered to express antigens that sense and kill pathogenic bacteria [14], suppress viral infections and reduce mite survival in bee colonies [16] and neutralize cholera toxins [17].

Panamanian golden frogs skin biota are diverse, with more than 3000 operational taxonomic units (OTUs) detected on captive frogs, that share $70 \%$ of their skin flora with wild frogs [18]. The skin flora is dominated by 15 core OTUs in the phyla Bacteroidetes, Actinobacteria, and Proteobacteria that are found on more than $90 \%$ of captive and wild frogs [18]. One of the core OTUs is a rod-shaped denitrifying bacteria in the genus Diaphorobacter, a genus that has also been found in sludge, air, and rice paddies [19-21]. Probiotics therapies with antifungal bacteria have been proposed as a way to directly inhibit $\mathrm{Bd}$ growth $[22,23]$. There is evidence that this approach can help to prevent or reduce $\mathrm{Bd}$ infections in vitro and in vivo through the production of potent antifungal metabolites including violacein produced by Janthinobacterium and prodigiosin from Serratia

\footnotetext{
${ }^{1}$ Smithsonian's National Zoo and Conservation Biology Institute, Center for Species Survival, Front Royal, VA, USA. ${ }^{2}$ Synthetic Biology Center, Department of Biological Engineering, Massachusetts Institute of Technology, Cambridge, MA, USA. ${ }^{3}$ Maryland Zoo in Baltimore, Baltimore, MD, USA. ${ }^{4}$ Smithsonian's National Zoo and Conservation Biology Institute Reptile Discovery Center, Washington, DC, USA. ${ }^{5}$ Department of Environmental Science and Policy, George Mason University, Fairfax, VA, USA. ${ }^{6}$ Smithsonian's National Zoo and Conservation Biology Institute, Center for Conservation Genetics, Washington, DC 20001, USA. ${ }^{7}$ Present address: Liberty University Department of Biology and Chemistry, Lynchburg, VA, USA. ${ }^{凶}$ email: gratwickeb@si.edu
} 
[12,24-27]. When probiotic Serratia bacteria were genetically modified in a knockout experiment to impair the production of prodigioson, frogs fared worse when exposed to $\mathrm{Bd}$ [28]. Despite these examples, previous probiotic supplementation of Panamanian golden frog skin with antifungal microbes did not mitigate the disease $[29,30]$. In these previous experiments, probiotics sourced from other amphibian species were applied individually to the frogs and they colonized the skin poorly, or did not achieve sufficient densities to have a protective function, leading to a reexamination of our probiotic approach.

We tested two novel probiotic strategies to reduce Bd infections in Panamanian golden frogs. First, we sampled the microbiota on the skin of captive Panamanian golden frogs, characterized the microbiome using 16S rRNA sequencing, and attempted to isolate the most prevalent and abundant strains of bacteria defined as core microbes [18]. These were selected as candidates for genetic manipulation to include the violacein pathway, which is wellcharacterized and reproducible $[12,25,27,31]$. By using a core skin microbe that is known to thrive on golden frog skin [18], we hoped to avoid a negative immune response from the frog to the probiotic treatment [32], and achieve sufficient threshold densities to obtain a probiotic effect $[12,29]$. Second, we aimed to increase the likelihood that probiotics would persist on the frog skin using a multi-genus consortium approach postulated to be more effective at mitigating disease than single-species probiotic treatments [33,34]. We mixed a 'cocktail' of several different anti-Bd bacteria isolated from Panamanian golden frogs, and even though some were similar to previous probiotic isolates attempted $[12,29]$, we expected that sourcing the probiotic bacteria from golden frogs would result in strains that are better adapted to golden frog skin.

\section{MATERIALS AND METHODS \\ Golden frog animal handling and skin microbiome experiments}

We received endangered species permits from the USFWS (FWS/DMA/PRT067210) and IACUC approvals from the Maryland Zoo in Baltimore, and the National Zoological Park (\#14-35). We subsampled 200 animals from all existing genetic lines of surplus-bred Panamanian golden frogs held at the Maryland Zoo in Baltimore. We swabbed each animal twice, ten times on the belly, ten times on each thigh, and 5 times on each foot [35]. DNA from the first swab was extracted for $16 \mathrm{~S}$ amplicon sequencing [18] (details below) to identify species based on their $16 \mathrm{~S}$ gene similarity to sequences deposited in the Ribosomal Database Project (RDP) [36], and relative abundance of bacteria on the frog skin used to identify core skin microbes. We chose a subset $(n=18)$ of these individuals that carried potential antiBd bacteria identified in a global database [37], and the second swab was cryopreserved in a glycerol solution from these 18 animals to culture and isolate the bacteria on R2A media plates [38].

\section{Measurement of Bd inhibition by skin isolates}

To determine which golden frog bacterial isolates secreted anti-Bd metabolites, we used an in vitro challenge assay in a 96-well plate format using spectrophotometry [30] with Bd strain JEL 423 and selected cultured isolates from the 18 golden frogs mentioned above. These bacteria were chosen based on relatedness to core golden frog microbes or to known putative anti-Bd isolates [37] based on 16S rRNA gene sequence similarity.

\section{Screen for antibiotic resistance of skin isolates}

Single colonies were inoculated into $2 \mathrm{~mL}$ of Luria Broth (LB) in $15 \mathrm{~mL}$ culture tubes (Fischer Scientific 352059) and incubated overnight at $30^{\circ} \mathrm{C}$ and $250 \mathrm{rpm}$ in a New Brunswick Scientific Innova 44. In the morning, starter cultures were diluted 1:200 in $2 \mathrm{~mL}$ of fresh LB medium and incubated for $4 \mathrm{~h}$ at the same temperature and speed. After $4 \mathrm{~h}$, cultures were serially diluted and plated onto LB agar plates containing antibiotics. Strains were deemed resistant to an antibiotic when the ten-fold dilution resulted in colonies.

\section{Cloning strains, media and chemicals}

Escherichia coli strain NEB10 ( $\triangle$ (ara-leu) 7697 araD139 fhuA $\triangle$ lacX74 galK16 galE15 e14- $\$ 80$ dlacZ $\Delta$ M15 recA1 relA1 endA1 nupG rpsL $\left(\mathrm{Str}^{\mathrm{R}}\right)$ rph spoT1 $\Delta$ (mrr-hsdRMS-mcrBC)), E. coli strain JTK164D ( $\mathrm{F}^{\prime} \Delta$ (ara-leu)7697 [araD139]B/r $\Delta$ (codB-lacl)3 galK16 galE15 $\lambda$ - e14- mcrA0 relA1 rpsL150(StrR) spoT1 mcrB1 hsdR2 $(r-m+)$ purM(pir TpR)), were used to construct all plasmids. E. coli strain HB101 (F- mcrB mrr hsdS20(rB- mB-) recA13 leuB6 ara-14 proA2 lacY1 galK2 $\mathrm{xyl}-5 \mathrm{mtl}-1 \mathrm{rpsL} 20\left(\mathrm{Sm}^{\mathrm{R}}\right)$ glnV44 $\lambda$-) containing helper plasmid pRK600 $\left(\mathrm{Cm}^{\mathrm{R}}\right)$ was used to perform conjugations. E. coli strains were grown at $37^{\circ} \mathrm{C}$ in LB medium (Becton Dickinson 244630). Strains isolated from frog skin were grown at $30^{\circ} \mathrm{C}$ in LB or Reasoner's $2 \mathrm{~A}$ (R2A) medium (Teknova R0005). Antibiotics and other chemicals were used at the following concentrations: carbenicillin $(100 \mu \mathrm{g} / \mathrm{mL})$ (Gold Bio C-103), kanamycin $(50 \mu \mathrm{g} / \mathrm{mL})$ (Gold Bio K-120), tetracycline $(10 \mu \mathrm{g} / \mathrm{mL})$ (Gold Bio $\mathrm{T}-101)$, spectinomycin $(100 \mu \mathrm{g} / \mathrm{mL}$ ) (Gold Bio S-140), chloramphenicol (35 $\mu \mathrm{g} / \mathrm{mL}$ ) (USB Corporation 23660), isopropyl $\beta$-D-1-thiogalactopyranoside (IPTG) (1 mM) (Gold Bio 12481C).

\section{Conjugation experiments}

Conjugation was selected as the method of introducing DNA to the bacteria because it is a relatively simple procedure that works for a wide range of species [39]. Plasmids were introduced to the golden frog skin microbe Diaphorobacter $63 \mathrm{~F}$ by conjugation using the triparental mating method. Briefly, single colonies of the $E$. coli donor strain, $E$. coli helper strain, and Diaphorobacter $63 \mathrm{~F}$ recipients were inoculated into $2 \mathrm{~mL}$ of $\mathrm{LB}$ medium with the appropriate antibiotics and grown overnight at $30^{\circ} \mathrm{C}$ and $250 \mathrm{rpm}$. In the morning, cells were concentrated by centrifuging overnight cultures and resuspending in a ten-fold smaller volume of fresh LB medium. All three strains were mixed at an equal ratio ( $10 \mu \mathrm{L}$ per strain) and spotted onto LB plates. Conjugations were incubated for $12 \mathrm{~h}$ at $30^{\circ} \mathrm{C}$. After the mating step, bacteria were scraped from the plates, resuspended in $1 \mathrm{~mL} L B$ and plated onto selective media. E. coli donor strain NEB10 $\beta$ was used for the conjugation of all BHR-containing plasmids and pir + donor strain JTK164D was used to conjugate the R6K plasmids for chromosomal integration.

\section{Violacein pathway engineering}

Violacein pathway genes from Chromobacterium violaceum ATCC 12472 were amplified from iGEM registry plasmids BBa_K274002 (vioABCE) (http://parts.igem.org/Part:BBa_K274002) and BBa_K598020 http://parts. igem.org/Part:BBa_K598020) (vioD). To construct the vioABDCE RBS library, oligonucleotides with ten degenerate bases upstream of the start codon (NNNTGNNNNNNRTG) were used to amplify each gene in the pathway. Golden gate reactions were used to combine the pieces together. The resulting library was transformed into $E$. coli and conjugated into the Diaphorobacter $63 \mathrm{~F}$ isolate using the triparental mating method described above. The sequence of the pathway selected is provided in Supplementary Table 1 . Violacein measurements and validation methods are detailed in Supplementary methods.

\section{Fluorescence measurements}

Single colonies were inoculated into $2 \mathrm{~mL}$ of LB medium containing kanamycin in $15 \mathrm{~mL}$ culture tubes (Fischer Scientific 352059) and incubated overnight at $30^{\circ} \mathrm{C}$ and $250 \mathrm{rpm}$. In the morning, starter cultures were diluted 1:200 in $2 \mathrm{~mL}$ of fresh media with or without IPTG and grown for $4 \mathrm{~h}$ at the same temperature and speed. After $4 \mathrm{~h}$, cultures were diluted 1:15 into phosphate-buffered saline and measured using a BD Biosciences Fortessa flow cytometer with a blue $(488 \mathrm{~nm})$ laser. An injection volume of $10 \mu \mathrm{L}$ and flow rate of $0.5 \mu \mathrm{L} / \mathrm{s}$ were used. Cytometry data were analyzed using FlowJo (TreeStar Inc., Ashland, OR) and populations were gated on forward and side scatter. The gated populations consisted of at least 30,000 cells. The median fluorescence of the gated populations was calculated using FlowJo.

\section{Doubling time measurement}

All strains were grown in incubated shakers at $250 \mathrm{rpm}$. Single colonies were inoculated into $2 \mathrm{~mL}$ of LB or R2A media in $15 \mathrm{~mL}$ culture tubes and incubated overnight at $30^{\circ} \mathrm{C}$ and $250 \mathrm{rpm}$. In the morning, starter cultures were diluted 1:500 in $150 \mu \mathrm{L}$ of fresh medium in black 96-well optical bottom plates (Thermo Scientific 165305) and incubated at $30^{\circ} \mathrm{C}$ with 1 $\mathrm{mm}$ orbital shaking in an Biotek Synergy $\mathrm{H} 1$ plate reader. Optical density measurements at $600 \mathrm{~nm}$ wavelength were made every $20 \mathrm{~m}$ for $12 \mathrm{~h}$. Doubling times were calculated using the slope of the linear portion of the growth curves during the exponential growth phase. 


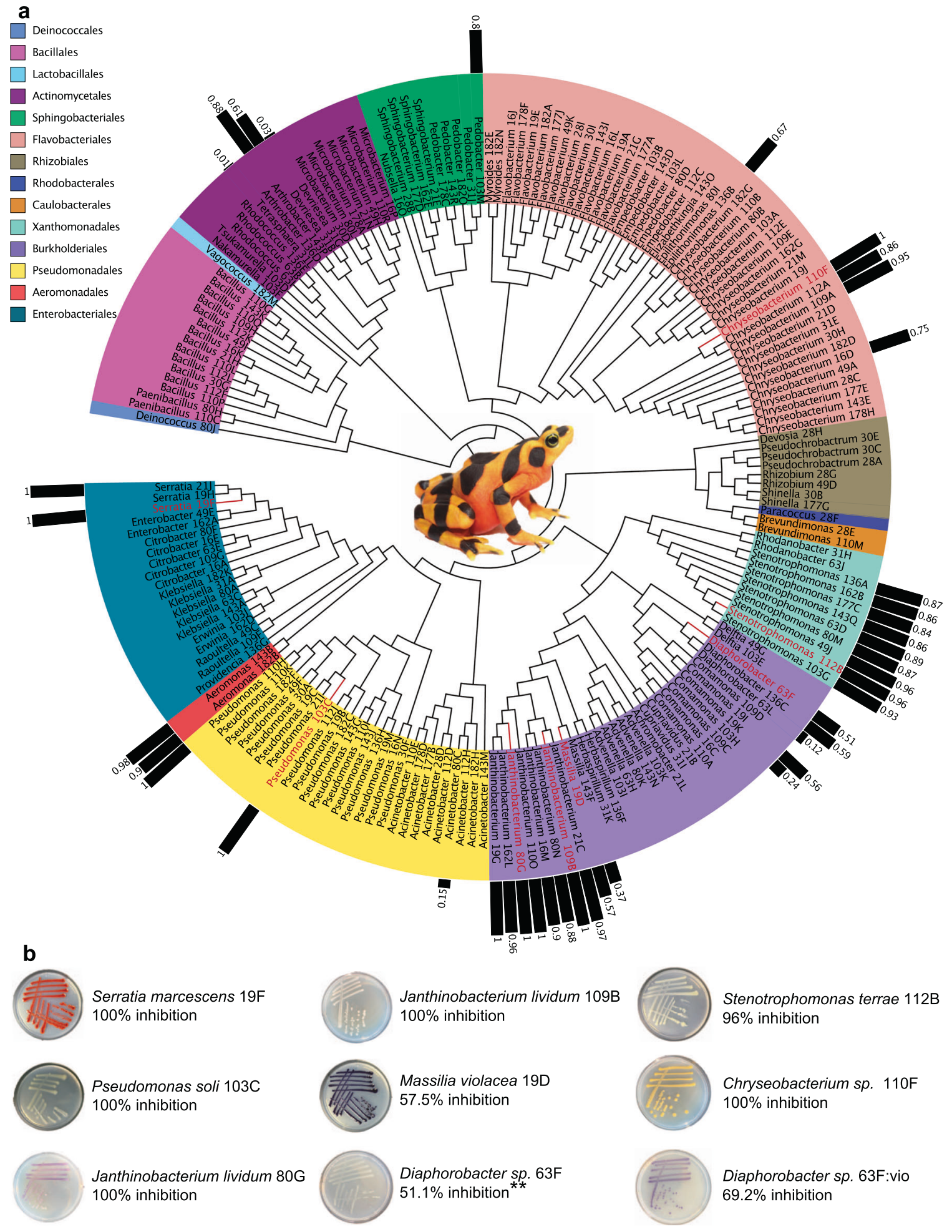

Fig. 1 Culture-dependent isolate analysis of captive Panamanian golden frogs. a Phylogenetic tree of bacteria cultured from the skin of 18 golden frogs screened for the presence of known anti-Bd bacteria. Bars represent strength of anti-Bd inhibition for a subsample of candidate probiotics identified from an existing database, isolates used in the final probiotic experiment are highlighted in red. $\mathbf{b}$ Inhibitory isolates selected for the probiotic consortium, note the genetically modified Diaphorobacter 63F:vio was included in the probiotic cocktail treatment. **The core skin microbe Diaphorobacter 63F wild-type strain was not used in probiotic consortium, but is shown here to illustrate the colony color prior to genetic modification.

\section{Treatment of golden frogs with probiotics}

We used 66 surplus-bred Panamanian golden frogs Atelopus zeteki provided by the Maryland Zoo in Baltimore, divided into the following treatment groups: Uninfected control $(n=10) ; \mathrm{Bd}(n=28) ; \mathrm{Bd}+63 \mathrm{~F}:$ vio $(n=12)$; and $\mathrm{Bd}+$ consortium $(n=17)$. Each frog was housed in an isolated cage (Supplementary Methods). For the Bd $+63 F$ :vio group we 
applied antibiotics for 3 days prior to probiotic treatment using $100 \mathrm{~mL}$ of a solution containing $12 \mathrm{mg} / \mathrm{L}$ cephalexin, $14.5 \mathrm{mg} / \mathrm{L}$ sulfamethoxazole, and $2.9 \mathrm{mg} / \mathrm{L}$ trimethoprim. The purpose of this treatment was to disrupt the pre-existing core Diaphorobacter community prior to exposure to the synthetic strain. The day following the last antibiotic treatment, $100 \mathrm{~mL}$ of a solution containing the genetically modified Diaphorobacter 63F:vio was administered every other day for 10 days using a dose of 375,000 cells $/ \mathrm{mL}$ for the first application, 750,000 cells $/ \mathrm{mL}$ for the second, and 1.5 million cells $/ \mathrm{mL}$ for the third, fourth, and fifth applications. The gradual increase of dose was conducted to reduce the likelihood of an immune shock reaction to the probiotics [32]. For the $\mathrm{Bd}+$ consortium group, no antibiotics were administered to the frogs, and $100 \mathrm{~mL}$ of a solution containing a total of 375,000 cells $/ \mathrm{mL}$ of each probiotic listed in Supplementary Table 2 plus the Diaphorobacter 63F:vio strain were administered every other day for 10 days, employing the strategy of a consistent low dose per strain with an overall high total bacterial dose. We administered sham $100 \mathrm{~mL}$ treatments to control and Bd animals by pouring $98 \mathrm{~mL}$ of sterilized reverse-osmosis (RO) water into sterilized cages, soaking several autoclaved sheets of brown paper towel in the process, and spraying $2 \mathrm{~mL}$ of RO water directly on to the frog (Supplementary Methods). We administered all antibiotic and probiotic treatments using the same method, but with RO water containing antibiotics or probiotics at the concentrations listed above.

\section{Exposure of golden frogs to $\mathrm{Bd}$}

On day 0 of the challenge experiment $(6 / 15 / 2016)$ individuals were placed in whirlpacks and exposed for $6 \mathrm{~h}$ to $20 \mathrm{~mL}$ of a solution containing 12,000 zoospores of Bd global pandemic lineage JEL 423 isolated from Hylomantis lemur in Panama. After the exposure period, the golden frogs were returned to their cages with the remaining Bd solution. During probiotic and $\mathrm{Bd}$ treatments, control individuals were treated exactly the same, but with RO water containing no added microorganisms. Daily husbandry of the golden frogs is provided in Supplementary Methods. The date of death of each frog was recorded in daily husbandry logs until the last day of the experiment $(9 / 13 / 16$, Day 90$)$ when the experiment was censored and all surviving golden frogs were humanely euthanized by immersion in a buffered, saturated solution of $10 \mathrm{~g} / \mathrm{L} \mathrm{MS222} \mathrm{[40].}$

\section{Sample collection and processing}

All living animals were swabbed on day 0 ( 1 day after probiotic treatment and 1 day before Bd exposure-week 0), on day 29 (week 4), and on day 57 (week 8). We extracted DNA from each swab with a Qiagen DNeasy blood and tissue kit (Valencia, CA, USA) following the manufacturer's protocol. We amplified extracted DNA for Bd analysis using qPCR methods [41], and quantified zoospore equivalents using standards prepared from Bd strain JEL 423. To assess cutaneous bacterial diversity via cultureindependent methods, we prepared extracted DNA for $16 \mathrm{~S}$ rRNA amplicon sequencing for weeks 0 and 4 [42], following methods previously described [18]. Briefly, DNA extracted from a sterile swab was included as a negative control in each set of extractions. We amplified prokaryotic DNA with primers that target the V4 region of the $16 \mathrm{~S}$ rRNA gene, pooled amplicons in equimolar ratios, size-selected the library by gel extraction with Qiagen QiaQuick Gel Extraction Kit, and purified the final library with the Qiagen QIAquick PCR Purification Kit (Qiagen, Valencia, CA, USA) following the manufacturer's protocol. We sequenced all samples and negative controls on an Illumina MiSeq instrument with $2 \times 250$ bp pairedend sequencing [42]. Bioinformatics and statistical analyses are detailed in Supplementary methods.

\section{RESULTS}

\section{Culturing skin microbes from Panamanian golden frogs}

We subsampled 200 animals from all existing genetic lines of surplus-bred Panamanian golden frogs held at the Maryland Zoo in Baltimore. The DNA from one swab was extracted and the $16 \mathrm{~S}$ rRNA gene was amplified using PCR in order to provide a cultureindependent evaluation of the most abundant bacteria on the frog skin [18]. The second swab was retained in a growth media containing glycerol [43] and then cryopreserved for culturing. We chose a subset $(n=18)$ of these frogs that carried putative/ predicted anti-Bd bacteria by comparing their OTUs to a global database of known anti-Bd microbes [37], and then cultured live bacteria from the second cryopreserved swab [38]. We identified isolates by amplifying and sequencing the 16S rRNA gene, and comparing it with $16 \mathrm{~S}$ rRNA genes deposited in the RDP [18,36]. In total, we were able to culture 193 bacterial isolates from 18 golden frogs (average $=10.7$ isolates per individual) (Fig. 1a). A majority of these isolates were identified as Gammaproteobacteria (31\%), Flavobacteria (24\%), and Betaproteobacteria (18\%). We also compared the culture-independent $16 \mathrm{~S}$ sequences collected from the 200 golden frogs with the cultured isolates' 165 sequences to identify whether or not we were able to culture any core bacteria that dominated the golden frog skin bacterial community (average relative abundance $\geq 1 \%$ and prevalence $\geq 90 \%$ on all golden frogs). We were able to culture 13 out of 22 core bacteria ( $\geq 98 \% 16 \mathrm{~S}$ rRNA gene sequence similarity); eight of these isolates served as candidates for genetic engineering (Table 1).

An in vitro challenge assay was performed with Bd strain JEL 423 and selected golden frog bacterial isolates to determine which isolates secreted anti-Bd metabolites (Fig. 1a) [30]. We selected the most inhibitory isolate from each of six different genera (that do not contain known amphibian pathogens) for a probiotic cocktail application to golden frogs prior to Bd exposure (Fig. $1 \mathrm{~b}$ and Supplementary Table 2). For one of these genera, Janthinobacterium lividum we selected two different morphotypes (white and purple) based on pre-existing interest in its probiotic potential [26,29] (Fig. 1, Supplementary Table 2).

Table 1. Core Skin Bacteria cultured from Atelopus zeteki skin that were screened for potential to genetically modify them to include the violacein pathway.

\begin{tabular}{|l|l|}
\hline $\begin{array}{l}\text { Culture-independent } \\
\text { OTU ID }\end{array}$ & $\begin{array}{l}\text { Relative } \\
\text { abundance (\%) }\end{array}$ \\
\hline 564487 & 10.3 \\
\hline 341094 & 3.2 \\
\hline 219549 & 2.8 \\
\hline 885496 & 2.5 \\
\hline denovo3687 & 2.5 \\
\hline 253429 & 2.3 \\
\hline 1140286 & 1.1 \\
\hline 4449458 & 0.9 \\
\hline
\end{tabular}

\begin{tabular}{|lll} 
Prevalence (\%) & $\begin{array}{l}\text { Sequence } \\
\text { similarity }\end{array}$ & $\begin{array}{l}\text { Culture-dependent } \\
\text { isolate ID }\end{array}$ \\
\hline 100 & 100 & $103 \mathrm{M}$ \\
\hline 97 & 98 & $143 \mathrm{P}$ \\
\hline 99 & 100 & $16 \mathrm{D}$ \\
99 & 100 & $31 \mathrm{~L}$ \\
99 & 100 & $31 \mathrm{G}$ \\
91 & 100 & $136 \mathrm{~B}$ \\
99 & 98 & $63 \mathrm{~F}$ \\
\hline 98 & 100 & $80 \mathrm{C}$ \\
\hline
\end{tabular}

RDP taxonomic identification (confidence estimate) Pedobacter sp. (100\%) Glutamicibacter sp. (100\%) Chryseobacterium sp. (100\%) Knoellia sp. (56\%) Devriesea sp. (62\%) Chryseobacterium sp. (100\%) Diaphorobacter sp. (97\%) Acinetobacter sp. (100\%)

${ }^{\mathrm{a} O T U}$ identification number from culture-independent analysis of 200 captive Atelopus zeteki

${ }^{\mathrm{b}}$ Average percent relative abundance among all golden frogs from culture-independent analysis $(n=200)$

cPrevalence among all golden frogs from culture-independent analysis $(n=200)$

${ }^{\mathrm{d}}$ Percent sequence similarity of the overlapping region (length $=253 \mathrm{bp}$ ) of $16 \mathrm{~S}$ rRNA gene between the culture-independent OTU consensus sequence and the culture-dependent isolate sequence 
a

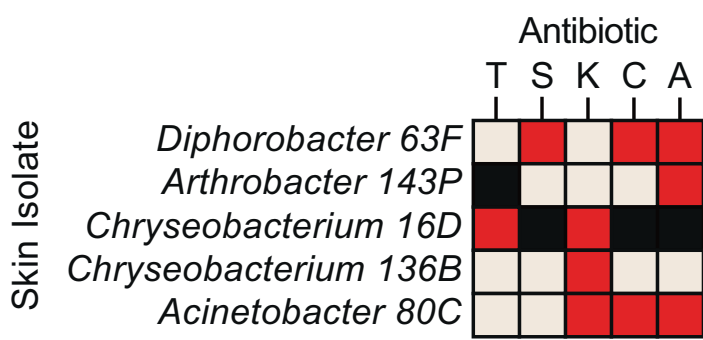

C b

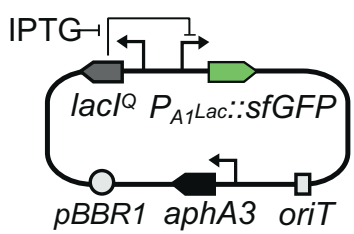

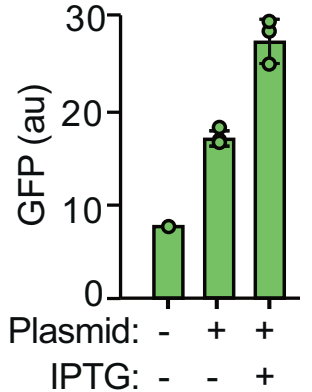

d

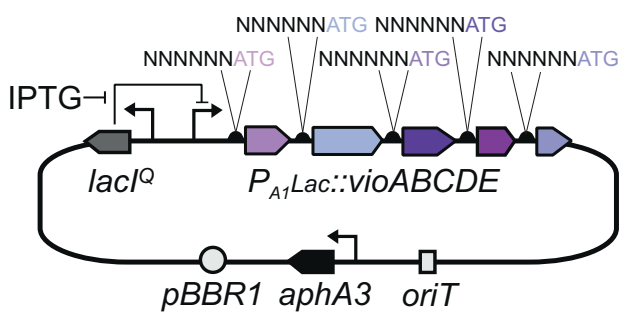

Protodeoxyviolaceinic acid (PVA)

Indole 3-pyruvic acid (IPA) imine

$\downarrow$ vio $B$

IPA imine dimer

\vioE<smiles>CC(C)(C)O[Mg]</smiles>

Deoxyviolacein

Protoviolaceinic acid

e

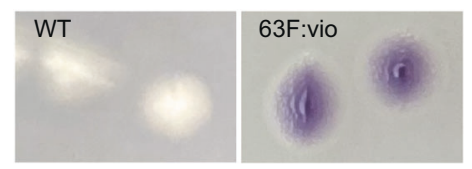

g

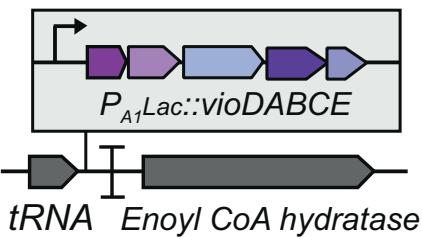

f

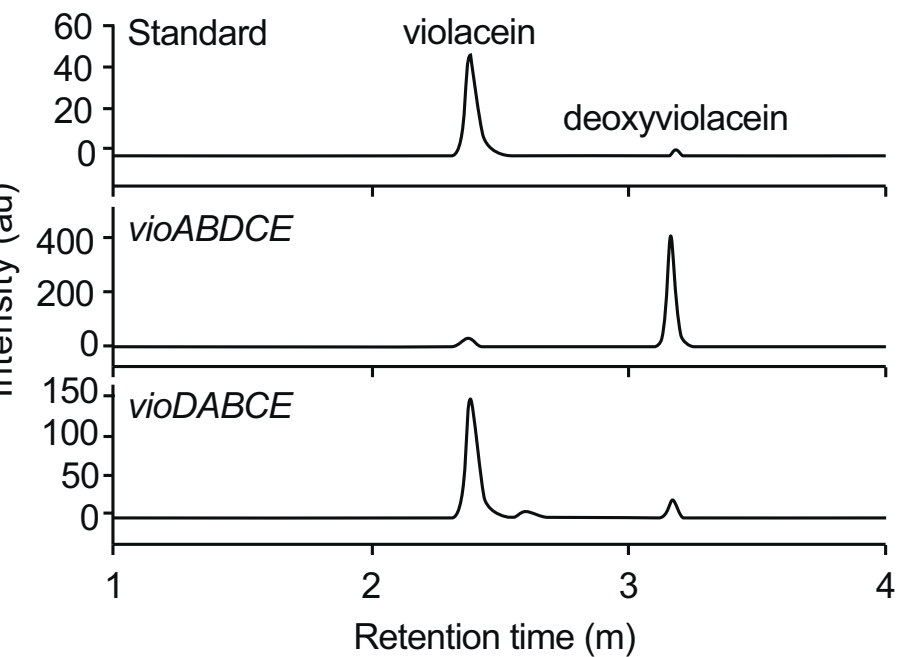

h

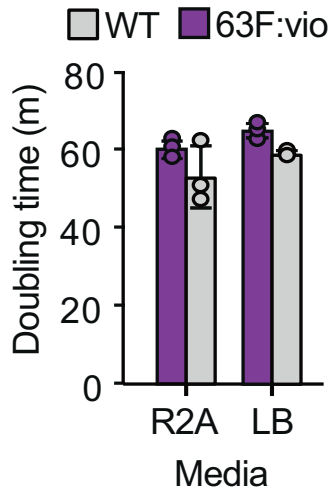

Fig. 2 Engineering violacein production into Panamanian golden frog bacterial isolates. a Skin isolates were tested for resistance to carbenicilin $(A, 100 \mu \mathrm{g} / \mathrm{mL})$, chloramphenicol $(C, 35 \mu \mathrm{g} / \mathrm{mL})$, kanamycin $(50 \mu \mathrm{g} / \mathrm{mL})$, spectinomycin $(\mathrm{S}, 100 \mu \mathrm{g} / \mathrm{mL})$, and tetracycline $(\mathrm{T}, 10 \mu \mathrm{g} /$ $\mathrm{mL}$ ). Strains were categorized as either resistant (red) or susceptible (pink) to the antibiotic ("Materials and methods"). Combinations that were not tested are colored black. b Fluorescence of Diaphorobacter $63 \mathrm{~F}$ strains with $(+)$ or without $(-)$ plasmid pJAB582 $\left(\mathrm{BHR}\right.$ lacl ${ }^{\mathrm{Q}} \mathrm{P}_{\mathrm{A} 1}$ lacO-1-sfGFP oriT aphA3). IPTG (1 mM) was added to induce expression of gfp from pJAB582. The bar graph shows the average of three replicates, dots represent individual data points, and error bars are the s.d. c Violacein biosynthetic pathway. $\mathbf{d}$ Plasmid containing violacein pathway library. Ribosome binding sites were randomized using degenerate primers ("Materials and methods"). e Image of 63F strains grown on R2A media for $72 \mathrm{~h}$ at $23^{\circ} \mathrm{C}$. $\mathbf{f ~ H P L C}-U V$ profiles of a violacein standard (top), 63F strain carrying plasmid pJAB631 (BHR $\mathrm{P}_{\mathrm{A} 1}$ lacO-1-vioABDCE oriT aphA3) (middle), and engineered Diaphorobacter 63F:vio strain containing $P_{A 1} l a c 0-1$-vioDABCE integrated into the genome (bottom). The identity of the peaks was determined by LC-MS. g Placement of the violacein pathway in the Diaphorobacter 63F chromosome. $\mathbf{h}$ Doubling times of wild type (gray) and engineered (purple) 63F strains. The bar graph shows the average of three replicates, dots represent individual data points, and error bars are the s.d.

\section{Engineering commensal bacteria to produce violacein}

We evaluated eight of the most abundant bacterial strains on golden frog skin that grew in culture for their potential to be genetically modified (Supplementary Table 2). We first measured the strains' resistance to several antibiotics that could be used for selection (tetracycline, spectinomycin, ampicillin, kanamycin). Strains that grew quickly in vitro (formed colonies after $48 \mathrm{~h}$ of growth at $30^{\circ} \mathrm{C}$ ) and were sensitive to at least one antibiotic were selected as candidates to introduce genes for violacein production (Fig. 2a). 
First, we attempted to deliver a broad host range plasmid (BHR origin of replication from broad host range plasmid pBBR1 [44] containing an isopropyl- $\beta-D-1$ thiogalactopyranoside (IPTG)-inducible green fluorescent protein (GFP) reporter into the frog skin strains, sequence of the plasmid provided in Supplementary Table 3. This plasmid confers resistance to kanamycin, therefore we first attempted to engineer the kanamycin-sensitive strains Diaphorobacter 63F and Glutamicibacter 143P. Conjugation was selected as the method of introducing DNA to the bacteria because it is a relatively simple procedure that works for a wide range of species ("Materials and methods") [39]. Only the Diaphorobacter isolate yielded kanamycin-resistant colonies after conjugation. Successful plasmid delivery was confirmed by PCR and GFP expression, as measured using flow cytometry (Fig. 2b). The addition of $1 \mathrm{mM}$ IPTG to cells grown in culture yielded a modest increase in fluorescence after $4 \mathrm{~h}$ in culture, indicating that the promoter worked and could be used to express recombinant genes in this species.

A library of violacein pathways was generated to produce the antifungal metabolite in Diaphorobacter 63F. Five enzymes (VioABCDE) from the violacein-producing bacterium Chromobacterium violaceum are needed to convert L-tryptophan into violacein (Fig. 2c) [31]. To express vioABDCE in Diaphorobacter, we made a large ribosome binding site (RBS) library by randomizing ten of the nucleotides upstream of each gene in the pathway (Fig. 2d). Pathway variants were cloned into a BHR ori plasmid and conjugated from $E$. coli to Diaphorobacter $63 \mathrm{~F}$ through a triparental mating and then plated and screened by eye. This method yielded two visibly purple colonies and violacein production was verified using LC-MS and both purple Diaphorobacter $63 \mathrm{~F}$ colonies were producing deoxyviolacein, a byproduct of the violacein biosynthetic pathway (Fig. 2f).

Genes in the biosynthetic pathway were then reordered to optimize violacein production. The undesired compound deoxyviolacein is produced when violacein precursor protodeoxyviolaceinic acid is hydroxylated by VioC instead of oxidized by VioD (Fig. 2c). Thus, we sought to increase vioD expression in order to reduce the generation of deoxyviolacein and produce violacein. To increase the expression of VioD, we moved the vioD gene to the start of our synthetic violacein operon. In bacteria, the first gene in bacterial operons is often the most highly expressed and expression decreases as a function of the distance from the transcription start site [45]. Therefore, moving vioD to the beginning of the operon should increase its relative expression level. Strains with the vioDABCE operon produced high levels of violacein and deoxyviolacein was no longer detected (data not shown).

The pathway was integrated into the Diaphorobacter $63 \mathrm{~F}$ genome to prepare the strain for transfer back to the golden frogs. Antibiotics are typically required for the maintenance of plasmids. Indeed, the violacein-containing plasmid was lost from Diaphorobacter 63F in the absence of kanamycin selection (data not shown). Since antibiotics would not be applied directly to the golden frogs after disease exposure, the violacein pathway was moved to the Diaphorobacter $63 \mathrm{~F}$ chromosome to increase the stability of the engineered trait. The operon was integrated at the end of a tRNA operon, between a tRNA-met(CAT) gene and its terminator (Fig. 2g). This location was selected to minimize the impact of the new DNA on host fitness. tRNAs are a common location for mobile genetic elements [46] and do not encode enzymes, such as sugar hydrolases [47] or amino acid synthases [48], that may be essential for survival in vivo. The tRNA operon was identified by ARAGORN (a tRNA/tmRNA detection software) [49]. A hypothetical enoyl coA hydratase was identified just downstream of the tRNA operon using BLAST. We constructed a suicide vector with the R6K origin of replication and regions of homology to both the tRNA and hydratase genes to integrate the violacein pathway into this location. The R6K origin requires a transfactor (pi protein) to replicate [50]. When conjugated into the Diaphorobacter 63F strain, which does not contain pi, the plasmid was forced to integrate. We screened kanamycin-resistant colonies for the presence of double-crossovers of the violacein pathway into the correct location and found several with the pathway integrated into the correct location. Production of violacein in the strains with the integrated pathway was verified by LC-MS (Fig. 2f). The resulting violacein-producing Diaphorobacter 63F strain was named Diaphorobacter 63F:vio.

When considering the reintroduction of the engineered commensal strain to the skin (Diaphorobacter 63F:vio), it is important that the violacein pathway not impart a fitness burden. To this end, we tested the fitness of the engineered strain, relative to the unmodified Diaphorobacter 63F strain by co-culturing the strains in non-selective media. In both rich and minimal media, we did not observe a difference in growth between the wild-type and engineered strain in vitro (Fig. $2 \mathrm{~h}$ ). The sequence of the plasmid to construct Diaphorobacter 63F:vio is located in Supplementary Table 1.

\section{Probiotic treatment of Panamanian golden frogs}

The Maryland Zoo in Baltimore provided 66 surplus-bred golden frogs, which we used to evaluate the ability for the engineered strain to colonize frog skin, produce violacein in this context and protect against $\mathrm{Bd}$ exposure. The golden frogs were divided into four treatment groups an uninfected control (control), Bd exposed (Bd), a probiotic treatment of the engineered core microbe Diaphorobacter 63F:vio after exposure to antibiotics/Bd exposed (Bd + 63F:vio), and a probiotic treatment including 63F:vio plus a natural consortium of seven anti-Bd golden frog bacteria (Fig. 3a \& 1b). The golden frogs were maintained for $24 \mathrm{~h}$ after the last probiotic treatment prior to $\mathrm{Bd}$ exposure. To assess cutaneous microbial community dynamics, we swabbed each individual 1 day after probiotic treatment (immediately before Bd exposure) (week 0) and day 29 (week 4).

Bacterial species richness as measured by amplicon sequence variant (ASV) richness differed strongly among treatments at week 0 (Fig. 3b). As expected, individuals treated with 63F:vio after an antibiotic pre-treatment had lower ASV richness in their skin microbiome than the control and $\mathrm{Bd}+$ consortium golden frogs without an antibiotic pre-treatment. Four weeks after golden frogs were exposed to $\mathrm{Bd}$, differences in bacterial species richness among all groups became less pronounced and were not statistically significant (Fig. 3b). Skin bacterial community composition among all treatment groups was similar at week 0 , except for the antibiotic-treated group 63F:vio that differed (Fig. 3b, Fig. S1). At week 4, skin bacterial community composition was similar among treatments in abundance-weighted composition (Fig. 3b), but differed in presence/absence composition (Fig. S1), indicating that dominant taxa were similar in abundances among treatments, but that less abundant bacterial taxa were present in some treatment groups and absent in others.

At the level of individual probiotics strains, the cocktail treatment approach resulted in Chryseobacterium 110F, and Stenotrophomonas $112 \mathrm{~B}$ colonizing the skin well, and persisting until week 4 (Fig. 4a). Janthinobacterium was also present on control animals but increased in abundance in consortium-treated groups (mean count of 679 vs 84 in non-consortium groups, Kruskal-Wallis chi-squared $=33.5, \mathrm{df}=3, p=2.471 \mathrm{e}-07$ ). Masilla 19D and Serratia 19F did not colonize or persist on the frog skin (Fig. 4a). The Pseudomonas $103 \mathrm{C}$ and 63F:vio strains both colonized the skin at week 0 , so were both present at the time of Bd inoculation, but did not persist to week 4 (Fig. 4a). The Diaphorobacter 63F:vio strain was distinguished from an unmodified, native Diaphorobacter strain by a single base-pair discrepancy in the $16 \mathrm{~S}$ gene sequence allowing us to distinguish between them for analysis purposes.

We conducted a validation step to verify the presence and operation of the synthetic violacein pathway on golden frog skin. 
a

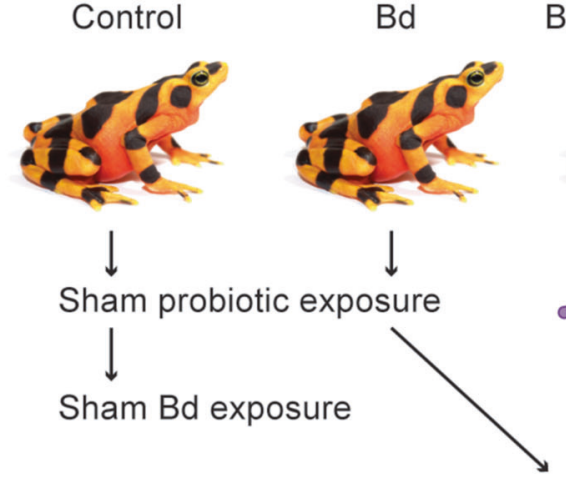

$\mathrm{Bd}+$ consortium

$B d+63 F: v i o$
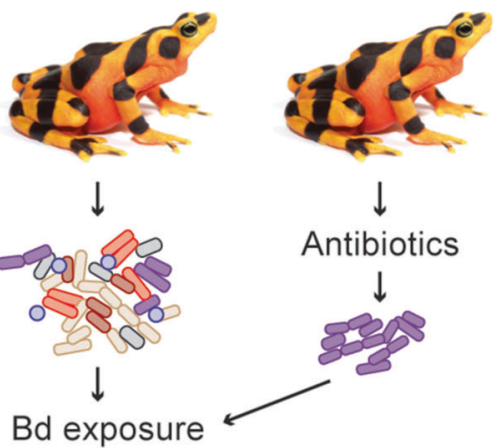

Antibiotics

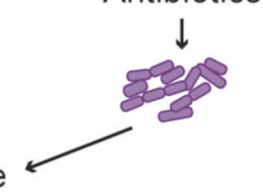

b

24 hrs post probiotic (week 0)
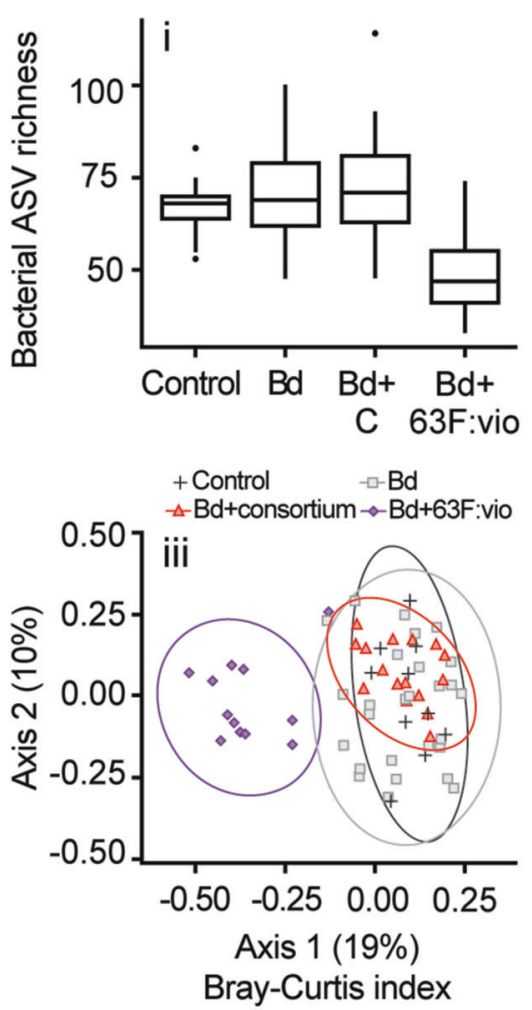

4 weeks post Bd exposure(week 4)
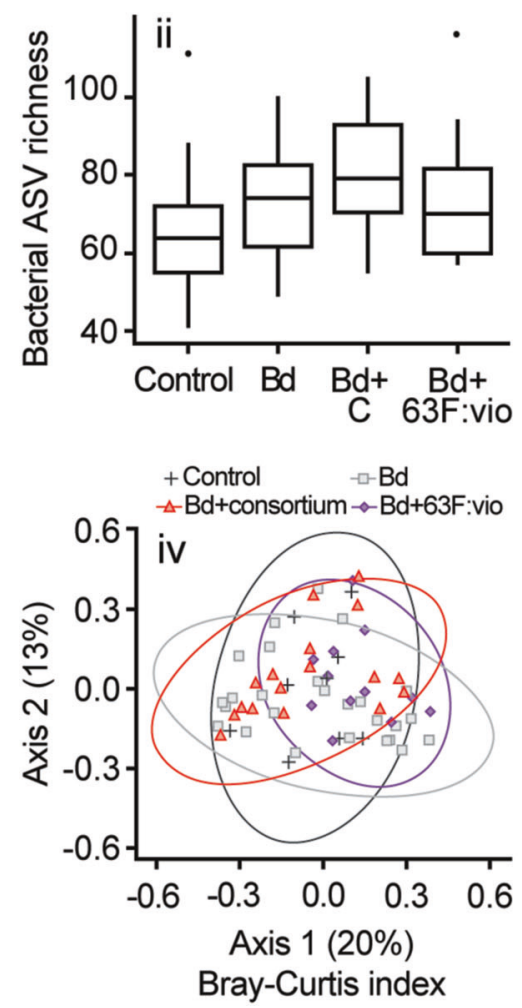

Fig. 3 Bacterial community dynamics due to experimental treatment. a Treatments applied to Panamanian golden frogs. b Bacterial community response to experimental treatments, week 0 samples were taken $24 \mathrm{~h}$ after probiotic treatment and just prior to Bd exposure, and 4 week samples were taken 4 weeks after Bd exposure. Bacterial amplicon sequence variant (ASV) richness at week 0 was significantly different (ASV richness ANOVA, $F_{2,62}=14.22, p<0.001$ ), but not at week 4 (ASV richness ANOVA $p=0.24$ ). Bacterial community composition (Bray-Curtis abundance-weighted index) at week 0 differed among all treatments (PERMANOVA, Pseudo $F_{2,62}=8.1, R^{2}=20.1 \%, p=0.001 ;$ all pairwise $p<0.003$ ), but not at week 4 (PERMANOVA all pairwise $p>0.12$ ).

At week 0 , we detected the pathway on 10/12 (83\%) individuals only treated with the synthetic bacteria $(\mathrm{Bd}+63 \mathrm{~F}: \mathrm{vio})$, and $3 / 16$ $(18 \%)$ individuals treated with the probiotic consortium $(\mathrm{Bd}+$ consortium). No control animals (0/36) tested positive for the pathway. By week 4, we could not detect the synthetic violacein pathway, or the modified microbe on any golden frogs (Fig. 4a). The unmodified, native Diaphorobacter strain was wellrepresented on all individuals at the start of the experiment, but was extremely reduced by both probiotic treatments that included Diaphorobacter 63F:vio (Fig. 4a). By week 4 however, the Diaphorobacter 63F:vio had completely disappeared from the frogs' skin, and was replaced by a pre-existing Diaphorobacter suggesting that there may have been an in vivo fitness cost to adding the violacein gene (Fig. 4a).

We also evaluated the effectiveness of the probiotic treatments to inhibit Bd growth and increase frog survival. All Bd-exposed animals became infected and remained infected for the duration of the experiment, with loads increasing over time and no differences among Bd-treatment groups (Fig. 4b). Similarly, there was no difference in survival between any of the Bd-treated groups, but all the control uninfected animals survived (Fig. 4c). We took a subset of skin swab samples from three individuals that had been treated with Diaphorobacter 63F:vio and 2 control individuals at week 0 and week 4 to test for violacein production 


\begin{tabular}{|c|c|c|c|c|c|c|c|c|}
\hline \multirow[t]{2}{*}{$\mathbf{a}$} & \multicolumn{2}{|c|}{ Control } & \multicolumn{2}{|c|}{$\mathrm{Bd}$} & \multicolumn{2}{|c|}{ Bd+63F:vio } & \multicolumn{2}{|c|}{$\mathrm{Bd}+$ Consortium } \\
\hline & 0 & 4 & 0 & 4 & 0 & 4 & 0 & 4 \\
\hline \multicolumn{9}{|l|}{ Janthinobacterium $109 B+80 G$} \\
\hline \multicolumn{9}{|l|}{ Chryseobacterium 110F } \\
\hline \multicolumn{9}{|l|}{ Stenotrophomonas $112 B$} \\
\hline \multicolumn{9}{|l|}{ Massilia 19D } \\
\hline \multicolumn{9}{|l|}{ Serratia $19 F$} \\
\hline \multicolumn{9}{|l|}{ Pseudomonas } \\
\hline \multicolumn{9}{|l|}{ Diaphorobacter 63F:vio } \\
\hline Diaphorobacter $63 F^{*}$ & & & & & & & & \\
\hline
\end{tabular}
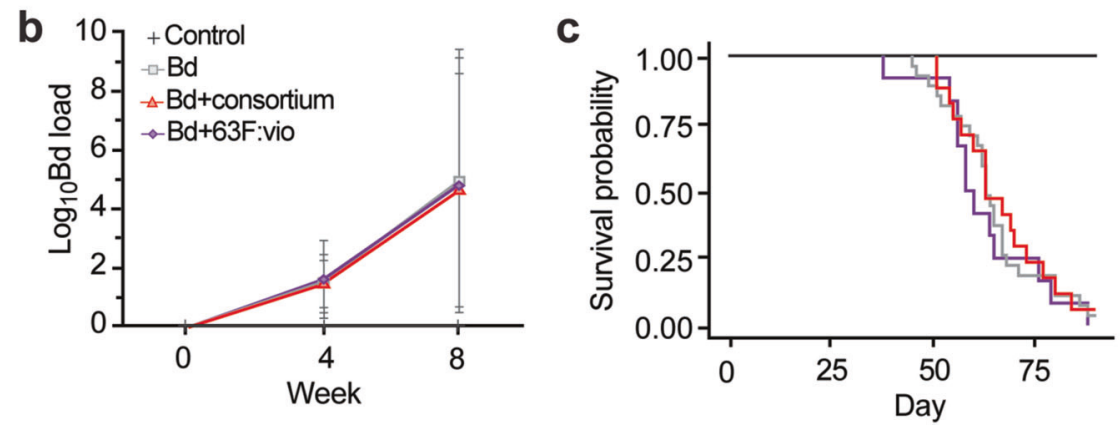

Fig. 4 Probiotic, pathogen, and host outcomes. a Heatmap of probiotic species present on the frogs with different treatment regimes in weeks 0 and 4 respectively. Each stripe represents $16 \mathrm{~S}$ frequency counts on an experimental animal (arranged in the same order for each timepoint). * Core Diaphorobacter refers to an ASV read present of on $86.3 \%$ of Week 0 and Week 4 individuals not treated with probiotics (b) $\mathrm{Bd}$ infection intensity in the 3 Bd-treatment groups and the uninfected control (Shown as $\log _{10}+1$-transformed zoospore equivalents \pm standard error). Differences in Bd loads in Bd-exposed frogs between weeks 4 and 8 were significant (Repeated measures ANOVA, Chisq $=$ $361.4,1 \mathrm{DF}=1, p=<2 \mathrm{e}-16^{* * *}$, but the effects of probiotic treatment on Bd load in Bd-exposed frogs were not significant (Chisq $=0.903,2$ $\mathrm{DF}, p=0.636)$. c Survival probability plot showing no difference in survival of $A$. zeteki between any of the Bd-exposed groups (Log-Rank test, Chisq $=0.6,2 \mathrm{df}, p=0.7$ ).

via LC-MS. At both timepoints, we were unable to detect violacein in any samples. Thus, while the engineered bacteria were able to initially colonize the frog skin, they are lost rapidly and do not produce the desired compound in detectable quantities or have the desired therapeutic effect in this context.

\section{DISCUSSION}

We have made great progress in understanding microbiomes, and discovering associations likely connected with useful applied function. However, few studies have achieved success at manipulating microbiomes for a desired function, highlighting major gaps in our understanding of microbial community ecology and function $[51,52]$. Despite some successful, or partly successful examples of probiotic therapies being used to reduce $\mathrm{Bd}$ in amphibians $[24,25,53,54]$ many probiotic treatments attempted so far in amphibians do not reduce Bd or improve survivorship when exposed to $B d[29,30,55-57]$. There are many potential pitfalls when selecting a probiotic therapy requiring a species-specific approach [22], in particular, research on probiotic selection and persistence is required [58]. Major factors that affect probiotic colonization and persistence include host defenses, competition with resident microbes, and resource availability. In this study, we focused on developing and testing two novel strategies to overcome these key challenges that have affected the success of previous probiotic studies.

The probiotic treatments in this study temporarily altered the community composition of the frog skin microbiome, and the observed community-level changes in the synthetic Diaphorobacter 63F:vio treatment group are likely attributable to the antibiotic treatment which temporarily disrupted the pre-existing frog skin microbiome. Despite the apparently successful colonization of the Diaphorobacter 63F:vio and other seven probiotic strains at the time of $\mathrm{Bd}$ exposure, neither probiotic treatment limited $\mathrm{Bd}$ infection. It seems likely that none of these bacteria achieved a threshold density necessary to protective anti-Bd metabolite concentrations, a problem noted in many other probiotic therapies $[12,29,59]$. Our observations serve as a cautionary message to those attempting to develop probiotic therapies-it is difficult to predict in vivo microbiome functions derived from in vitro observations. Four out of eight probiotic microbes did not persist on the frog skin to week 4 . This could be because the bacteria were poorly adapted to persist on the frog skin, despite initially being isolated from golden frogs, because of competition between probiotics or the pre-existing community [60], or that hosts upregulated skin defenses (e.g. antimicrobial peptides) to clear probiotic treatments [32].

In the case of the synthetic Diaphorobacter 63F:vio strain, the antibiotic treatment combined with direct supplementation of 63F:vio seems to have reduced the population of a prevalent preexisting Diaphorobacter, but after week 4, the synthetic microbe had disappeared from the skin and been replaced by this preexisting Diaphorobacter. We verified that the engineered and nonmanipulated strains competed successfully in vitro. It is not clear if the genetic manipulation directly reduced the competitive ability of the microbe in vivo, but it is known that strains that have undergone many cycles of culturing can lose functional traits that affect adhesion [58]. In hindsight, further research into the competitive function and persistence of the synthetic microbe would have been informative prior to Bd exposure. However, the fact that there was no observed survival or reduction in infection 
rates, even though the probiotic treatment communities clearly included significant populations of the synthetic microbe at the time of Bd exposure make it doubtful that solving the persistence issue would have led to the desired disease outcome. The only core bacteria that we were successfully able to engineer (Diaphorobacter 63F), unfortunately, had a $1 \%$ average relative abundance in the $200 \mathrm{~A}$. zeteki sampled prior to the experiment. It is worth considering that a better probiotic outcome may have been achieved by integrating the violacein gene pathway into a more abundant core bacteria (than Diaphorobacter 63F) or by using several engineered core microbes (Table 1).

The community-level microbiomes of consortium-treated golden frogs became less distinguishable with time after probiotic treatments. Prior to Bd exposure, the consortium treatments had a strong effect-being exposed to a probiotic consortium or the synthetic 63F: vio probiotic changed microbiome composition from the control state, but reverted to communities with common and numerically dominant bacteria similar to control animals later. Previous studies often detect changes in microbiome composition related to $\mathrm{Bd}$ $[61,62]$, but in this case, we did not detect community-level microbiome differences due to $\mathrm{Bd}$ infection. Therefore, the post-Bd exposure homogenization of probiotically treated frog skin microbiomes are not likely due to Bd effects, but are simply reverting to pre-probiotic treatment states. We would normally expect to see an effect of Bd load on the microbial community [62], but the relative $\mathrm{Bd}$ loads at week 4 were comparatively low (Fig. 3a), so a lack of observed community-level effect is not remarkable.

Here, we implemented a strategy to introduce a genetic function needed by an endangered species into its microbiome. We used a consortium of probiotic candidates that were previously isolated from golden frogs, that were applied multiple times prior to Bd exposure, and for the first time, used a core skin microbe that had been successfully genetically modified to have a proven anti-Bd function. It is disappointing that we were unable to obtain the desired disease outcome. Indeed, it has been observed in other contexts, such as the human microbiome, that the establishment of an engineered bacterium in a persistent colonization of a host remains a challenge [63-65]. More basic research to understand the factors governing microbiome community assembly in relation to the host immune systems and pathogens will be needed to improve our ability to manipulate these systems in order to achieve a desired function. This example explores both the promise of microbial therapies and genetic engineering, and the challenges that we still face in understanding and manipulating microbiome communities and their function.

\section{REFERENCES}

1. Scheele BC, Pasmans F, Skerratt LF, Berger L, Martel A, Beukema W, et al. Amphibian fungal panzootic causes catastrophic and ongoing loss of biodiversity. Science. 2019;363:1459-63.

2. La Marca E, Lips KR, Lotters S, Puschendorf R, lbanez R, Rueda-Almonacid JV, et al. Catastrophic population declines and extinctions in neotropical harlequin frogs (Bufonidae: Atelopus). Biotropica. 2005;37:190-201.

3. Lewis CHR, Richards-Zawacki CL, Ibáñez R, Luedtke J, Voyles J, Houser $P$, et al. Conserving Panamanian harlequin frogs by integrating captive-breeding and research programs. Biol Conserv. 2019;236:180-7.

4. Bosch J, Sanchez-Tomé E, Fernández-Loras A, Oliver JA, Fisher MC, Garner TW. Successful elimination of a lethal wildlife infectious disease in nature. Biol Lett. 2015;11:20150874-20150874.

5. Garner TW, Schmidt BR, Martel A, Pasmans F, Muths E, Cunningham AA, et al. Mitigating amphibian chytridiomycoses in nature. Philos Trans R Soc Lond B Biol Sci. 2016;371:20160207.

6. Park MK, Ngo V, Kwon YM, Lee YT, Yoo S, Cho YH, et al. Lactobacillus plantarum DK119 as a probiotic confers protection against influenza virus by modulating innate immunity. PLoS ONE. 2013;8:75368.

7. Lin T, Liu X, Xiao D, Zhang D, Cai $Y$, Zhu X. Lactobacillus spp. as probiotics for prevention and treatment of enteritis in the lined seahorse (Hippocampus erectus) juveniles. Aquaculture. 2019;503:16-25.
8. Chrostek E, Hurst GDD, McGraw EA. Infectious diseases: antiviral Wolbachia limits dengue in Malaysia. Curr Biol. 2020;30:R30-R32.

9. Reid G, Younes JA, Van der Mei HC, Gloor GB, Knight R, Busscher HJ. Microbiota restoration: natural and supplemented recovery of human microbial communities. Nat Rev Microbiol. 2011;9: 27-38.

10. Cheng TL, Mayberry H, McGuire LP, Hoyt JR, Langwig KE, Nguyen H, et al. Efficacy of a probiotic bacterium to treat bats affected by the disease white-nose syndrome. J Appl Ecol. 2017;54:701-8.

11. Mao N, Cubillos-Ruiz A, Cameron DE, Collins JJ. Probiotic strains detect and suppress cholera in mice. Sci Transl Med. 2018;10:1-8.

12. Becker MH, Brucker RM, Schwantes CR, Harris RN, Minbiole KPC. The bacterially produced metabolite violacein is associated with survival of amphibians infected with a lethal fungus. Appl Environ Microbiol. 2009;75:6635-8.

13. Auclair J, Frappier M, Millette M. Lactobacillus acidophilus CL1285, Lactobacillus casei LBC80R, and Lactobacillus rhamnosus CLR2 (Bio-K+): Characterization, manufacture, mechanisms of action, and quality control of a specific probiotic combination for primary prevent. Clin Infect Dis. 2015;60:S135-S143.

14. Chua KJ, Kwok WC, Aggarwal N, Sun T, Chang MW. Designer probiotics for the prevention and treatment of human diseases. Curr Opin Chem Biol. 2017:40:8-16.

15. Smanski MJ, Zhou H, Claesen J, Shen B, Fischbach MA, Voigt CA. Synthetic biology to access and expand nature's chemical diversity. Nat Rev Microbiol. 2016;14:135-49.

16. Leonard SP, Powell JE, Perutka J, Geng P, Heckmann LC, Horak RD, et al. Engineered symbionts activate honey bee immunity and limit pathogens. Science. 2020;367:573-6.

17. Paton AW, Morona R, Paton JC Bioengineered Bugs expressing oligosaccharide receptor mimics: Toxin-binding probiotics for treatment and prevention of enteric infections. Bioeng Bugs. 2010;1:172-7.

18. Becker MH, Richards-Zawacki CL, Gratwicke B, Belden LK. The effect of captivity on the cutaneous bacterial community of the critically endangered Panamanian golden frog (Atelopus zeteki). Biol Conserv. 2014;176:199-206.

19. Liu Y, Zhu HH. Diaphorobacter polyhydroxybutyrativorans Qiu et al. 2015 is a later heterotypic synonym of Diaphorobacter nitroreducens Khan and Hiraishi 2003. Int J Syst Evol Microbiol. 2019;69:2954-7.

20. Pham VH, Park SJ, Roh $Y$, Roh DH, Rhee SK. Diaphorobacter oryzae sp. nov., isolated from a thiosulfate-oxidizing enrichment culture. Int J Syst Evol Microbiol. 2009;59:218-21.

21. Kim SJ, Moon JY, Ahn JH, Weon HY, Hong SB, Seok SJ, et al. Diaphorobacter aerolatus sp. nov., isolated from air, and emended description of the genus Diaphorobacter. Int J Syst Evol Microbiol. 2014;64:513-7.

22. Bletz MC, Loudon AH, Becker MH, Bell SC, Woodhams DC, Minbiole KP, et al. Mitigating amphibian chytridiomycosis with bioaugmentation: characteristics of effective probiotics and strategies for their selection and use. Ecol Lett. 2013;16:807-20.

23. Woodhams DC, Bletz M, Kueneman J, McKenzie V. Managing amphibian disease with skin microbiota. Trends Microbiol. 2016;24:161-4.

24. Muletz CR, Myers JM, Domangue RJ, Herrick JB, Harris RN. Soil bioaugmentation with amphibian cutaneous bacteria protects amphibian hosts from infection by Batrachochytrium dendrobatidis. Biol Conserv. 2012;152:119-26.

25. Harris RN, Brucker RM, Walke JB, Becker MH, Schwantes CR, Flaherty DC, et al. Skin microbes on frogs prevent morbidity and mortality caused by a lethal skin fungus. ISME J. 2009;3:818-24.

26. Kueneman JG, Parfrey LW, Woodhams DC, Archer HM, Knight R, McKenzie VJ. The amphibian skin-associated microbiome across species, space and life history stages. Mol Ecol. 2014;23:1238-50.

27. Woodhams DC, LaBumbard BC, Barnhart KL, Becker MH, Bletz MC, Escobar LA, et al. Prodigiosin, violacein, and volatile organic compounds produced by widespread cutaneous bacteria of amphibians can inhibit two Batrachochytrium fungal pathogens. Microb Ecol. 2017;75:1-14.

28. Madison JD, Ouellette SP, Schmidt EL, Kerby JL. Serratia marcescens shapes cutaneous bacterial communities and influences survival of an amphibian host. Proc R Soc B Biol Sci. 2019;286.

29. Becker MH, Harris RN, Minbiole KP, Schwantes CR, Rollins-Smith LA, Reinert LK, et al. Towards a better understanding of the use of probiotics for preventing chytridiomycosis in Panamanian golden frogs. Ecohealth. 2011;8:501-6.

30. Becker $M H$, Walke JB, Cikanek $S$, Savage $A E$, Mattheus $N$, Santiago $C N$, et al. Composition of symbiotic bacteria predicts survival in Panamanian golden frogs infected with a lethal fungus. Proc R Soc B. 2015;282:20142881.

31. August PR, Grossman TH, Minor C, Draper MP, MacNeil IA, Pemberton JM, et al. Sequence analysis and functional characterization of the violacein biosynthetic pathway from Chromobacterium violaceum. J Mol Microbiol Biotechnol. 2000;2:513-9.

32. Küng D, Bigler L, Davis LR, Gratwicke B, Griffith E, Woodhams DC. Stability of microbiota facilitated by host immune regulation: informing probiotic strategies to manage amphibian disease. PLoS ONE. 2014;9:e87101. 
33. Antwis RE, Harrison XA. Probiotic consortia are not uniformly effective against different amphibian chytrid pathogen isolates. Mol Ecol. 2018;27:577-89.

34. Piovia-Scott J, Rejmanek D, Woodhams DC, Worth SJ, Kenny H, McKenzie V, et al. Greater species richness of bacterial skin symbionts better suppresses the amphibian fungal pathogen Batrachochytrium dendrobatidis. Microb Ecol. 2017;74:217-26.

35. Van Sluys M, Kriger KM, Phillott AD, Campbell R, Skerratt LF, Hero JM. Storage of samples at high temperatures reduces the amount of amphibian chytrid fungus Batrachochytrium dendrobatidis DNA detectable by PCR assay. Dis Aquat Organ. 2008;81:93-97.

36. Wang Q, Garrity GM, Tiedje JM, Cole JR. Naïve Bayesian classifier for rapid assignment of rRNA sequences into the new bacterial taxonomy. Appl Environ Microbiol. 2007;73:5261-7.

37. Woodhams DC, Alford RA, Antwis RE, Archer $\mathrm{H}$, Becker MH, Belden LK, et al. Antifungal isolates database of amphibian skin-associated bacteria and function against emerging fungal pathogens. Ecology. 2015;96:595.

38. Lauer A, Simon MA, Banning JL, Lam BA, Harris RN. Diversity of cutaneous bacteria with antifungal activity isolated from female four-toed salamanders. ISME J. 2008;2:145-57.

39. Simon R, Priefer U, Pühler A. A broad host range mobilization system for in vivo genetic engineering: Transposon mutagenesis in gram negative bacteria. Bio/ Technology. 1983;1:784-91.

40. AVMA. AVMA guidelines on euthanasia; 2007. Schaumburg: American Veterinary Medical Association.

41. Boyle DG, Boyle DB, Olsen V, Morgan JT, Hyatt AD. Rapid quantitative detection of chytridiomycosis (Batrachochytrium dendrobatidis) in amphibian samples using real-time Taqman PCR assay. Dis Aquat Organ. 2004;60:141-8.

42. Caporaso JG, Lauber CL, Walters WA, Berg-Lyons D, Lozupone CA, Turnbaugh PJ, et al. Global patterns of $16 \mathrm{~S}$ rRNA diversity at a depth of millions of sequences per sample. Proc Natl Acad Sci USA. 2011;108:4516-22.

43. Lauer A, Simon MA, Banning JL, André E, Duncan K, Harris RN. Common cutaneous bacteria from the eastern red-backed salamander can inhibit pathogenic fungi. Copeia. 2007;2007:630-40.

44. Antoine R, Locht $C$. Isolation and molecular characterization of a novel broadhost-range plasmid from Bordetella bronchiseptica with sequence similarities to plasmids from Gram-positive organisms. Mol Microbiol. 1992;6:1785-99.

45. Lim HN, Lee $Y$, Hussein R. Fundamental relationship between operon organization and gene expression. Proc Natl Acad Sci USA. 2011;108:10626-31.

46. Williams KP. Integration sites for genetic elements in prokaryotic tRNA and tmRNA genes: sublocation preference of integrase subfamilies. Nucleic Acids Res. 2002;30:866-75.

47. Härtl B, Wehrl W, Wiegert T, Homuth G, Schumann W. Development of a new integration site within the Bacillus subtilis chromosome and construction of compatible expression cassettes. J Bacteriol. 2001;183:2696-9.

48. Gu A-M, Frandsen N, Stragier P. Plasmids for ectopic integration in Bacillus subtilis. Gene. 1996;180:57-61.

49. Laslett D, Canback B. ARAGORN, a program to detect tRNA genes and tmRNA genes in nucleotide sequences. Nucleic Acids Res. 2004;32:11-16.

50. Kittleson JT, Cheung S, Anderson JC. Rapid optimization of gene dosage in E. coli using DIAL strains. J Biol Eng. 2011;5:1-7.

51. Sheth RU, Cabral V, Chen SP, Wang HH. Manipulating bacterial communities by in situ microbiome engineering. Trends Genet. 2016;32:189-200

52. Yong E. I contain multitudes: the microbes within us and a grander view of life. New York: HaperCollins Publishers; 2016.

53. Harris R, Lauer A, Simon M, Banning J, Alford R. Addition of antifungal skin bacteria to salamanders ameliorates the effects of chytridiomycosis. Dis Aquat Organ. 2009;83:11-16.

54. Kueneman JG, Woodhams DC, Harris R, Archer HM, Knight R, McKenzie VJ. Probiotic treatment restores protection against lethal fungal infection lost during amphibian captivity. Proc R Soc B Biol Sci. 2016;283:1-7.

55. Robak MJ, Richards-Zawacki CL. Temperature-dependent effects of cutaneous bacteria on a frog's tolerance of fungal infection. Front Microbiol. 2018;9:410.

56. Woodhams DC, Rollins-Smith LA, Reinert LK, Lam BA, Harris RN, Briggs CJ, et al. Probiotics modulate a novel amphibian skin defense peptide that is antifungal and facilitates growth of antifungal bacteria. Microb Ecol. 2020;79:192-202.

57. Walke JB, Becker MH, Loftus SC, House LL, Teotonio TL, Minbiole KP, et al. Community structure and function of amphibian skin microbes: an experiment with bullfrogs exposed to a chytrid fungus. PLoS ONE. 2015;10:0139848.

58. McKenzie VJ, Kueneman JG, Harris RN. Probiotics as a tool for disease mitigation in wildlife: Insights from food production and medicine. Ann N Y Acad Sci. 2018;1429:18-30.

59. Donia MS. A toolbox for microbiome engineering. Cell Syst. 2015;1: 21-3.

60. Niederle MV, Bosch J, Ale CE, Nader-Macías ME, Aristimuño Ficoseco C, Toledo LF, et al. Skin-associated lactic acid bacteria from North American bullfrogs as potential control agents of Batrachochytrium dendrobatidis. PLoS ONE. 2019;14:e0223020.
61. Muletz-Wolz CR, Fleischer RC, Lips KR. Fungal disease and temperature alter skin microbiome structure in an experimental salamander system. Mol Ecol. 2019;28: mec.15122.

62. Jani AJ, Briggs CJ. The pathogen Batrachochytrium dendrobatidis disturbs the frog skin microbiome during a natural epidemic and experimental infection. Proc Natl Acad Sci USA. 2014;111:E5049-E5058.

63. Kearney SM, Gibbons SM, Erdman SE. Orthogonal dietary niche enables reversible engraftment of a gut bacterial commensal. 2018;24:1842-851.

64. Shepherd ES, Deloache WC, Pruss KM, Whitaker WR, Sonnenburg JL. An exclusive metabolic niche enables strain engraftment in the gut microbiota. Nature. 2018;557:434-8.

65. Lee SM, Donaldson GP, Mikulski Z, Boyajian S, Ley K, Mazmanian SK. Bacterial colonization factors control specificity and stability of the gut microbiota. Nature. 2013;501:426-9.

\section{ACKNOWLEDGEMENTS}

MHB was supported by a National Zoo/Smithsonian Office of Fellowships Post-doctoral Fellowship. MHB and BG are grateful to the Smithsonian Scholarly Studies, U.S. Fish and Wildlife Service Division of International Conservation Amphibians in Decline Fund FY2014, F14AP00750, the Shared Earth Foundation, Susan and Frank Mars and an anonymous foundation for their generous financial support of this research project. This work was also supported by the U.S. Defense Advanced Research Projects Agency's Biological Robustness in Complex Settings program award to CAV [HR0011-15-2-0033]. We are grateful to the Maryland Zoo in Baltimore and the AZA Golden Frog Species Survival Program for their provision of animals for this research.

\section{AUTHOR CONTRIBUTIONS}

Author contributions following the CRediT taxonomy (https://casrai.org/credit/) are as follows: Conceptualization: MHB, BG, CAV, RCF, JANB; Data curation: CRM, MHB, JANB, AWK, Formal analysis: CRM, MHB, JANB, AWK, BG, Funding acquisition: MHB, BG, CAV, RCF, EB, Investigation: MHB, BG, JANB, KB, ME, EG, BK, AWK, EL, AJM; Project administration: BG; Supervision: BG, EB, CAV, RCF; Software: CRM, AWK, MHB, JANB; Visualization: $C R M, M H B, J A N B, B G$, Writing-original draft: BG; Writing-review \& editing: $M H B, B G, C A V, R C F$, JANB.

\section{COMPETING INTERESTS}

The authors declare no competing interests.

\section{ADDITIONAL INFORMATION}

Supplementary information The online version contains supplementary material available at https://doi.org/10.1038/s43705-021-00044-w.

Correspondence and requests for materials should be addressed to Brian Gratwicke

Reprints and permission information is available at http://www.nature.com/ reprints

Publisher's note Springer Nature remains neutral with regard to jurisdictional claims in published maps and institutional affiliations.

\begin{abstract}
Attribution 4.0 International License, which permits use, sharing, adaptation, distribution and reproduction in any medium or format, as long as you give appropriate credit to the original author(s) and the source, provide a link to the Creative Commons licence, and indicate if changes were made. The images or other third party material in this article are included in the article's Creative Commons licence, unless indicated otherwise in a credit line to the material. If material is not included in the article's Creative Commons licence and your intended use is not permitted by statutory regulation or exceeds the permitted use, you will need to obtain permission directly from the copyright holder. To view a copy of this licence, visit http://creativecommons. org/licenses/by/4.0/.
\end{abstract}

Open Access This article is licensed under a Creative Commons

This is a U.S. government work and not under copyright protection in the U.S.; foreign copyright protection may apply 2021, corrected publication 2022 